
History Research

Reseña

\section{Enric Saguer (ed.). Els cortals empordanesos, del segle XIII al XXI. Sis estudis. Girona, Biblioteca d'Història Rural (BHR), 2019, 249 pp. ISBN: 978-8499844978.}

Esta obra corresponde al conjunto de monografías publicadas por la Associació d'Història Rural de la Universidad de Girona. En este caso se trata de seis estudios de autores diferentes, todos ellos ligados, de una manera u otra, a dicha universidad.

Los cortals son un tipo de explotación agraria localizados en la bahía de Rosas, concretamente en las localidades de Castelló d'Empúries y Sant Pere Pescador. Son una variante local y muy específica de la Cataluña nororiental, que se diferencian, sin embargo, por su mayor extensión, la presencia de humedales y la vocación ganadera. A pesar de la especificidad del tema, como plantaré más adelante, puede tener un interés más general del que aparenta.

El libro consta de una introducción y seis capítulos o estudios, distribuidos de manera que las características y el pasado de los cortals se tratan en los primeros estudios, mientras que los posteriores se centran más bien en su presente y su proyección futura, su gestión y preservación como una forma de conservación de la naturaleza y el patrimonio cultural y social

La introducción general está a cargo de Enric Saguer y Mairsa Roig. La palabra cortal viene de cort, lugar cerrado para el ganado. Originariamente ganaderas (vacuno, caballar y ovino) estas explotaciones se dedicaron fundamentalmente a distintos tipos de agricultura de cereal, hasta llegar al cultivo del arroz. Las características de estas explotaciones, de las que muchas superaban las 30 ha, motivaba la utilización de una considerable mano de obra. Se trataba de trabajadores agrarios contratados a jornal y que residían mayoritariamente en las villas de Castelló y Sant Pere, o bien en los propios cortals, como vaqueros o mozos. Los salarios agrarios eran modestos, por lo que la conflictividad social a partir del siglo xviII fue alta, con una fuerte demanda de reparto de parcelas.

El primer capítulo (Josep Maria Gironella) se centra en la Baja Edad Media. En primer lugar, se discute la interpretación tradicional del origen de los cortals, que se supone que tendrían su origen en simples cabañas para la ganadería, en terrenos de marisma susceptibles de desecación. A finales del siglo xIV parece ser que existía ya un modelo bien consolidado, tanto por el número como por las características y emplazamiento. La modificación humana de los humedales había reducido su espacio e introducido cultivos de cereal y ganadería. Esto, junto con la existencia de canales de escorrentía resulta familiar para quien conozca la agricultura de las zonas del noreste mallorquín (Muro y Santa Margalida). Tal vez el origen de los repobladores de estas zonas no resulte ninguna coincidencia, ya que estos espacios de Mallorca formaban parte de las baronías de los condes de Ampurias y el obispo de Girona, por lo que se presume que la mayoría de los repobladores procedían de estas áreas.

El segundo capítulo (Pere Gifre) abarca los siglos xVII y xVIII, en los que el sistema agrario cortaler ya estaba bien asentado, y la producción agraria, basada más en la expansión del cereal que de la ganadería, era creciente. Aunque se vería limitada por las vicisitudes bélicas de la época, también cabe pensar que la demanda de las tropas fuera estimulante para un activo mercado de la tierra. Estas circunstancias adversas no dieron lugar, sin embargo, a un excesivo endeudamiento.

El tercer capítulo (Marisa Roig) cronológicamente corresponde a los siglos xix y xx, aunque se centra sobre todo en el análisis de los hogares cortalers y la dinámica de la población. Se completa el estudio con un interesante análisis de la movilidad y la socialización. Las fuentes utilizadas no son tan solo documentales, sino que se recurre adecuadamente a descripciones literarias y a la historia oral, con entrevistas personales. Una conclusión importante que destacar es el interés de las diversas familias por mantenerse en una misma explotación y buscar otras para sus descendientes, construyendo una inmensa red endogámica (perceptible en las frecuencias de los apellidos). Esa peculiaridad se debe al relativo aislamiento respecto de los grandes núcleos de población.

El cuarto capítulo (Enric Saguer) consiste en el análisis pormenorizado de un caso concreto en el primer tercio del siglo $\mathrm{xx}$, a través del estudio de su contabilidad. Se trata de una contribución poco frecuente, ya que estas contabilidades familiares no suelen conservarse o suelen ser muy sesgadas. Se trataba de una explotación regida por criterios plenamente mercantiles en cuanto a decisiones productivas y de venta. Saguer señala que el camino elegido por los propietarios de este cortal era individualista, lo que le permite calificarlo de plenamente capitalista, en disonancia con las tendencias asociativas y cooperativistas de la época.

El quinto capítulo (Rosa Congost y Enric Saguer) trata sobre la aparcería y el acceso a la propiedad. La visión tradicional de la aparcería siempre ha hecho hincapié en la facilidad de acceso a la propiedad. En el caso de los cortals, sin embargo, la aparcería se sustituyó frecuentemente por el arrendamiento fijo y por el cultivo directo. Parece ser que mucho más que el propio régimen contractual la causa fue la evolución de la tasa de sustracción. Dentro de una problemática generalizada al campo catalán, la aparcería fue el campo de batalla entre propietarios y aparceros. Después de la guerra civil y la victoria franquista, paradójicamente, los propietarios se quejaban de la dificultad de imponer un régimen de aparcería, y se puede observar una tendencia de las familias masoveras a acceder a la propiedad.

El sexto capítulo (Meritxell Fernández) aborda el estado de los cortals en la actualidad, sobre todo en relación con los pla- 
nes de urbanización, de carácter predominantemente turístico, y los movimientos de defensa de la naturaleza.

Como he señalado anteriormente, este tipo de estudios monográficos, a pesar de su carácter localista, permite establecer interesantes conexiones con otras áreas, como el noreste de Mallorca. En esta zona, la presencia de humedales como S'Albufera de Muro, hizo que uno de los principales problemas para el desarrollo de la agricultura se solventara a base de canales de escorrentía (albellons), que alternaban con el regadío. Las grandes dimensiones de las explotaciones y la ganadería extensiva vacuna, en torno a la Albufera, también resultan características similares, así como una expansión del cereal que culminaría con el cultivo del arroz. Resultaría interesante establecer hasta qué punto esto se debe a la repoblación con gentes procedentes del Ampurdán o se trata, simplemente, de la coincidencia que supone resolver los mismos problemas agroambientales de manera semejante. Actualmente, sin embargo, un observador superficial no vería grandes coincidencias entre los paisajes de la bahía de Rosas y la costa del Noreste mallorquín, donde el triunfo de la especulación inmobiliaria ha hecho que los espacios agrarios originarios resulten prácticamente una reliquia (no así, sin embargo, en el interior). La modesta pero efectiva presión social para la protección ambiental de las tierras ampurdanesas tuvo mucha menos importancia en tierras mallorquinas, con evidentes resultados.

Ricard Soto Company Universitat de Barcelona

https://doi.org/10.33231/j.ihe.2020.12.008 